\title{
ARABIC KEY CONSONANTS
}

\author{
Zev bar-Lev
}

\section{SAN DIEGo STATE UNIVERSITY}

This article outlines an approach to lexicon in Arabic linguistics, with special implications for teaching Arabic as a foreign language. Its basic insight is that individual initial consonants have their own meanings. On a theoretical level, this key-consonant system offers a pervasive theoretical insight about the structure of a lexicon, and the nature of lexical acquisition; and on a practical level, it offers a powerful key to learning vocabulary in L2 - which in turn may offer the best possible validation of the theoretical claim. It is here related to insights in linguistic theory on the submorpheme (and analogical modeling); in L2 learning, such submorphemes can help make learning of vocabulary easier, and sometimes even make it possible to guess the meanings of new roots in context. An additional implication for the history of Semitic linguistics is also drawn, proposing to bring back into Semitic linguistics a set of insights that had been "banished" from the mainstream with the advent of "scientific" Semitic grammar over a thousand years ago. On the other hand, we will draw a sharp distinction between the proposal and biconsonantal root theory, with which it might be confused on first impression.

\section{THE KEY-CONSONANT SYSTEM}

This article ${ }^{1}$ outlines an innovative approach to lexicon in Arabic linguistics and language teaching, which I call the key-consonant system, and which, at the time of this writing, I had been formulating for the last two to three years, on the basis of a similar system that I have been developing for Hebrew for some seven (or twenty-five) years. The essence of the proposal is that single initial consonants have separate meanings of their own in Semitic; that is, they are initial single-segment submorphemes (to be called key-consonants). This is a synchronic study, and includes whatever loan-words (borrowed roots) conform to the analysis. The system, if validated, has important implications for the psychological problem of L1 vocabulary, providing a partial answer to the question of how humans can acquire tens of thousands of words, and then access

${ }^{1}$ I am grateful to Jeff Kaplan of San Diego State University for much interesting feedback and useful suggestions on my work on key-consonants; and to Ghada Osman of San Diego State University for her help on all matters Arabic. (However, I alone am responsible for all errors.) 
them while producing and comprehending language (in speech and writing).

Significance for linguistic theory implies applicability to other languages, and I will ultimately suggest that this aspect of the present proposal is most interesting-more so, in its own way, than the consonantal-root structure of Semitic. In particular, the present proposal of initial single-segment submorphemes (key-consonants) in Hebrew and Arabic may offer support for a similar analysis of other languages, which is not at all as obvious per se in languages such as English. Bolinger (1965, 1968), who originated submorpheme-theory, focused on initial consonant clusters. I will return to this question specifically later.

The proposal has practical implications for the teaching and learning of L2 vocabulary, in that it offers the potential for making this most difficult aspect of Arabic more accessible to more learners; this, in contrast with the fact that grammar (syntax, morphology, phonology) has been the main structural focus for language teaching, and dictionaries are left as mostly unanalyzed masses of data, an unending burden that learners must "carry around" (both physically and metaphorically), stuck in the depressing truth that, no matter how long they study the language, they will never match the native speaker's lexicon, with its tens of thousands of words (or, almost as imposing, many thousands of roots).

Far from all valid theoretical claims have any practical application whatsoever. So when a set of descriptive observations with implications for linguistic theory is pervasive and basic enough to be usable in foreign-language courses, this suggests an unusual degree of significance. My investigations have left me no doubt of the pervasiveness and potential of key-consonant theory for both Hebrew and Arabic. For Hebrew, I have already developed them into a range of exercises that I have been using, for three to four years, from the second semester of instruction. Students differ in their ability to use the system, and certainly its specific applicability varies considerably from instance to instance. But most of my Hebrew students can by now guess meanings in context with specially constructed exercises. They naturally have far more difficulty in the uncontrolled environment of ordinary text, but I have already seen so many cases of individual "triumphs" with ordinary students and ordinary texts that their general applicability in L2 learning of Hebrew is beyond question for me, and in fact seems to prove itself more deeply each semester.

Constructing equivalent pedagogical materials for Arabic will have to await a few more revisions of the Arabic descriptive materials. Fortunately, both tasks will benefit from my prior experience in Hebrew, tele- 
scoping the future development. My key-letter lexicon of Arabic already contains the overwhelming majority of roots in Wehr's (1976) dictionary, and I have made significant progress in rearrangements along the lines of those I did a few years ago for Hebrew.

When I began plowing through the Arabic dictionary a few years ago (just as I had thirty years ago for Hebrew), I quickly lost any doubt of the pervasiveness of the system for Arabic too, although the system is quite different from that of Hebrew in specifics. I have not yet convinced myself that the Arabic system is quite as simple and coherent as in Hebrew, which certainly impacts on its practical implications, but I am convinced of its relevance at least to L1 vocabulary acquisition in Arabic, and am confident that it has some applicability to the study of Arabic as a foreign language, although perhaps not quite so early in the curriculum.

In Hebrew, I have called the system the key-letter system (bar-Lev 1999b, 2000a, 2001 a, 2003a, 2003b, 2004, 2006). My focus on letters in preference to phonemes is justified by two considerations: First, in Hebrew, the system applies slightly better to reading and to written language, due to the historical separation between phonemes and letters. Second, it is clear to me that the system functions somewhat more practically in written language, for it is only in written language that the learner has the time to actually use the system while processing. (The system applies to consonants only, that is, only those phonemes that are always represented in ordinary Hebrew or Arabic spelling.) This second consideration applies to Arabic as well as Hebrew, but to emphasize the general-linguistic relevance of the research, I will use the more generally applicable term key-consonant.

In the exposition below, I will return to several issues two or more times, adding some new dimension to the discussion each time. For example, English submorphemes will be mentioned several times, beginning with Bolinger's initial proposal, and finally culminating in a reanalysis of English submorphemes through the light shed on them by key-consonant theory. Even on issues where the development of ideas is not so dramatic, such as the contrast with biconsonantal root theory, I have found that scholars in Semitic linguistics so often and so pervasively assume that key-consonant theory is just another version of biconsonantal root theory that it is well worth going over the contrast from several points of view, throughout the article. (A tighter exposition of the contrast in one place might be too easily missed, or might convince less well, simply because it would then be so localized.) In both kinds of cases, references and examples must be repeated - all to the greater good of clear communication, that is, to give the reader a better-rounded idea 
of the whole concept and its implications - and avoid misapprehensions that I have found to be all too common. Thus the article will not follow the linear logic typical of Western academic writing - rather the use of a more Semitic organization should perhaps not be considered inappropriate in the present context.

\section{Implications}

One of the interesting implications of the key-consonant system is the reanalysis it suggests of the history of Semitic linguistics: In such a reanalysis, Bolinger had been preceded by insights in Semitic linguistics by more than a millennium. We will try to sort out this complex history below, distinguishing between two separate and distinct contributions to submorpheme-theory in earlier Semitic linguistics.

At the moment, the system is merely a proposal for the synchronic (that is, structural) analysis of Arabic; but even now it is such that these implications can at least be exemplified. The noted implications for the history of Arabic and Semitic linguistics will be discussed momentarily, although its most far-reaching implications are for teaching of Arabic, as implied above.

One of the thorny issues that we will have to deal with is how proposals about the structure of lexicon can be validated empirically. Numerical estimates of the extent of conformity to a theory of lexicon would seem desirable - except that such estimates would presuppose a complete theory of semantic features that simply does not exist. For guidance we will look, as examples, to a theory that is widely assumed to be validated: the system of voices in Semitic. (I use the handy and appropriate term voices to replace the confusing term forms (of the verb)-Arabic bin $\bar{a}^{\supset}$; Hebrew binyan.)

The system was first formulated for Hebrew out of a practical effort to create a handy word-list for intermediate students of Hebrew. The need to provide a comprehensive list of roots for purposes of reading seemed daunting until the principle of key-consonants presented itself; this principle made possible a one-page dictionary, in which root-meanings are listed by key-consonant only, and a set of exercises which have been used with several generations of Hebrew students, beginning in earnest in the second semester.

Of what use is a one-page dictionary? Is it of any more value than a telephone book that gives only the first digit of any telephone number? And what do these exercises show about the system's implications for structural linguistics?

Lexicon (the vocabulary of a language) is the "elephant in the living 
room" of language teaching and theoretical research. There is no real theory of it: It is viewed as a listing of arbitrary items (like a telephone book), with no internal structure apart from the listing (and not even alphabetic). It is barely an accepted field of linguistic research - at best a small one, lexicology, devoted to deciding the difference between homonymy and polysemy. This identity problem rears its head especially in language teaching, where the learner is sent home to memorize some listing of words (or roots, in Arabic) for the next day's quiz - a listing that might at best have topical coherence. Given the little systematic attention that is devoted to lexicon, one might think that syntax, morphology, phonology, and the like, are most important in language learning, where in fact the lexicon has far greater importance. However many subtleties of syntax and morphology one knows, they are wasted without a large vocabulary.

But how does one become an advanced learner in Arabic? Is there any help for this language, as it competes in the university marketplace with languages like Spanish, and their thousands of cognates like revolución, gramática, and the like?

Guessing from context is one often recommended strategy-but learners of Arabic know that it is a difficult business unless (or even if) a teacher is present to confirm one's guesses (and fill them in when they are absent!).

Wouldn't it be wonderful if there were some way that a learner could, for example, choose between alternate guesses?

What if we had an unknown word/root in a context, e.g. "The teacher $\mathrm{X}$-es the book"? It is certainly possible to guess either "open" or "close." But what if there were some sort of key accompanying the word, such as a picture or icon floating above it, perhaps as in Table 1, (a) two arrows pointing away from each other, vs. (b) a flat line.

Table 1. Hypothetical Icons.
(a) $\leftarrow \rightarrow$
(b) -

If the icon is (a), we could take this as a hint that the correct choice is "open"; if (b), then "close." In fact, this example works in Arabic, according to the key-consonant system: $\boldsymbol{f}$ in Arabic, according to the keyconsonant system, means split, and $s$ means smooth, which would predict that the Cairene Arabic il-mucallim yiftah il-bāb would mean "the teacher opens the door," while il-mucallim yisakkar il-bāb means "the teacher closes the door."

This example is deliberately simple, but in principle more complex 
examples work the same way. Some of the complexity or subtlety of the system is in fact shown in this example: While the connection between "open" and split is clear enough, the connection between "close" and smooth is less so, and required the 'special training' of the icon.

On a larger scale, as I have seen from Hebrew, it is by no means always possible to guess unknown roots from context. Whether a guess is possible at all itself depends on many unpredictable factors. But we can reasonably assume (without experimental proof) that any system that helps accurate guessing (even sometimes) will more importantly help in learning vocabulary generally, by providing a structure to the previously unstructured lexicon.

A 'one-page dictionary' sounds like a preposterous idea. Of what purpose is it to have roots included by first-letter alone? It can be valuable only if key-consonant theory is empirically valid. If it is valid (and only if), then it makes sense to use it as a tool for decoding. It will work as the memory sometimes does, fixating on the first consonant of a word: 'I seem to remember a word beginning with a $\boldsymbol{p}$ that means something like the top of a mountain.' If you are reading for meaning, this memory is sufficient (if correct). As noted, a one-page dictionary of a language makes sense only if the key-consonant system is valid; if not, then all letters will have the same sets of meanings. Even in the key-consonant system, the letters do overlap, of course; but not enough to undermine the potential usefulness - and the theoretical significance - of the onepage dictionary as a whole.

But I must repeat that the potential role of the key-consonant system in Arabic teaching is, for now, only a metaphor to prove (or at least suggest) to the reader the potential importance of the key-consonant system. For the present, I will attempt no more than to assess how closely my descriptive results for Arabic match the results that I have been using in Hebrew to demonstrate the pervasiveness and coherence of the system. The argument would seem persuasive: It is the pervasiveness and coherence of the system that determines its practical applicability.

The system of voices (forms of the verb) is itself fraught with complexities and irregularities, and yet it is a staple of Semitic language teaching - and familiarly assumed to be quite alive even in the modern Semitic languages. With all the irregularities and complexities of the key-consonant system, I have found it more useful than the 'voices' in Hebrew teaching: The 'voices' often require considerable guidance to use for all but the strongest students; key-consonants, at least in Hebrew, also require training to use, but even the weakest students have repeated "light bulb" moments with them, once they accept the basic idea. With 
my recent revisions in Arabic, I anticipate being able one day to elaborate a similar help for Arabic, whereby learners would be able to guess the meanings of unknown roots in context with significant help beyond the context itself, from the first consonant of the root.

The main question for me is what the system says about the Arabic language, and, just as important, how it may possibly help the learner of Arabic as a foreign language. On this second set of implications, let me emphasize: While I am most definitely attempting to outline a descriptive tool for the analysis of the vocabulary of Arabic, I also believe that (1) instructional applications are valuable and even interesting on their own; and (2) descriptive tools can prove their psychological reality (as structural claims) by way of foreign-language instructional applications. After all (under 2), not all structural insights can be formulated as instructional applications: Some are simply too advanced for most foreign learners, or too complicated to learn and apply.

\section{Linguistic Backgrounds.}

There is a common approach in Arabic linguistics, as also in Hebrew linguistics, to believe that "there is nothing new under the sun"- or, as it is sometimes said, "If it is new, it's not true; and if it is true, it's not new."

At first sight, the key-consonant system is often confused with biconsonantal (biliteral) root theory - the theory that the triconsonantal (triliteral) roots are derived from shorter roots by addition of a third consonant (see Hurwitz 1966, Bohas 1997, Ehret 1997, Mehandjiyska 1998, Diakonov 1975; also Hodge 1971, Kautsch 1910, Vicichl 1987, Zaborski 1975, 1991). Indeed, I did read Hurwitz (1963, reprinted from 1905) at about the time of my earliest research of roots and their meanings in Hebrew.

Key-consonant theory is, in effect, a uniconsonantal root theory: One should no more identify it with biconsonantal theory than the latter innovative theory should be identified with traditional triconsonantal root theory (which was innovative over a millennium ago)! One could, I suppose, regard the key-consonant system, from one point of view, as a "logical extension" of biconsonantal root theory. However, it could also be considered, with far better justification, a sub-theory of a wholly different older insight - with the interesting "twist" that the latter insight has not been a part of linguistics for well over a thousand years. Here are found the potential implications of the system for the history of Arabic linguistics.

In an obvious mathematical sense, the key-consonant system is a uniconsonantal root theory, and thus a "logical extension" of biconsonantal 
root theory: Once it has been proposed that 3-consonant roots can be derived from 2-consonant roots, it would seem natural to take the "next step" of positing 1-consonant roots.

Such a further step would seem natural, but in fact it has not generally been taken by Semitic linguists. Ehret (1995) is commonly associated with this next step - but in fact only some of his proposed roots are uniconsonantal. (For critique of this position, see Zaborski 1975, 1991.) Ehret currently (personal communication) tends to believe that as many as a few hundred roots of Proto-Afroasiatic were uniconsonantal-still just a small part of the roots of the total vocabulary of Proto-Afroasiatic. In any case, his proposal is a reconstruction of Proto-Afroasiatic, not an analysis of the structure of Arabic or Hebrew. Indeed, it seems to be generally agreed that even proto-Semitic was triconsonantal.

A more far-reaching biconsonantal theory is proposed by Bohas (1997), who proposes not only to derive Arabic 3-consonant roots from 2-consonant roots, but to further derive the latter from 'matrices' consisting of two positions of articulation, which can then be realized as various pairs of consonants within the two positions - and in either order. This theory is, both logically and as presented by Bohas (1997), even further from key-consonant theory, because of its adherence to two positions of articulation. The only trace that I find of uniconsonantal insight in Bohas (1997) is a brief note on a proposal of Diakonov (Bohas 1997, 49-51) that a final $\boldsymbol{b}$ indicates a wild animal. In any case, Bohas is, primarily and more ambitiously, heading in a different direction from key-consonant theory altogether, that of capturing alternations between consonants, and permutations of consonants, in Semitic roots. ${ }^{2}$ Bohas's theory is interesting, but it is not in any way uniconsonantal.

With the exception of Diakonov's note in Bohas and Ehret's few 1consonant roots, then, there is nothing here resembling key-consonant

2 Vychicl (1987), while regarding triconsonantal roots as a defining characteristic of the Semitic subfamily of Afro-Asiatic as distinct from the "Hamitic" languages (not a subfamily) in the family, while seeing these roots as "in numerous cases" deriving from "biconsonantal skeletons" (although "skeleton" refers to a consonantal root per se, not to its biconsonantal structure), and even asserting that the third consonant must have had some meaning - not necessarily the same one in each case - compares them to prefixes as in admit, omit, permit, etc. Bohas's theory of 'matrices' is similar, as noted - including the ultimate agreement with biconsonantality. I. M. Diakonoff (1975) discusses syllable structure, whether assuming triconsonantal roots or simply sidestepping the whole issue is not clear to me. (I am grateful to Grover Hudson, Chris Ehret, and Andrzej Zaborski for their suggestions and insights on this topic.) 
theory (at least not any more than the innovative 2-consonant theories resembles the traditional 3-consonant theory), except for the general insight that there is something "smaller" than the 3-consonant root. But if this connection is made to assess key-consonant theory as "unoriginal," then we could even argue about how original biconsonantal root theory is: Is it not a mere variant of root theory itself? Once we have taken the major step of dropping vowels out of the root, does not any further theory pale in originality before it?

In any case, another logical source - far more logically connected, in my opinion - can be found for key-consonant theory, namely the insight that individual consonants have single meanings. This insight is as old as Semitic linguistics: It is implicit in the very first line of the Sefer yetzirah (Kaplan 1997), which was written well before the eighth century, and on which $\mathrm{Sa}^{\mathrm{c}}$ adyah $\mathrm{Ga}^{\mathrm{D}}$ on, the first Hebrew grammarian, wrote a commentary. But his slightly younger contemporary Ibn Sīnā (Avicenna) may be the earliest to give an actual list of meanings for the consonants (Schimmel 1975, Lory 1996), since there is no trace of such a listing in the Sefer yetzirah, or Saadiya's commentary on it, or Saadiya's (surviving) grammatical and lexical writings.

Since Jewish-Arab contacts were vigorous at that time (Saadiya wrote in Arabic), it is quite possible that Ibn Sīnā was the originator of the explicit concept that individual letters have lexical meanings. It may be seen as partly consistent with the views of grammarians like Mĕnahem ben Saruq (W. Chomsky 1972, 168), who assumed 1-consonant, 2-consonant, and 3-consonant roots. But such insights seem to have been banished from Semitic grammar with the advent of 3-consonant root theory, called by some (e.g., W. Chomsky 1972, 171) the beginnings of 'scientific grammar.' At that point, we could say, grammar and mysticism (like alchemy and chemistry) separate from each other-Sefer yetsirah having been both the first work of Hebrew grammar, and also the first separate work of Jewish mysticism: kabbalah.

A trace of the key-consonant insight is found in the early versions of Gesenius's lexicon (see Miller 1966), where Hebrew bayit "house" is related to be- "in." But otherwise, after 3-consonant root-theory became established as the mainstream, this insight is best attested in mysticism, such as the thirteenth-century Sefer ha-zohar (Bar Yohai 5758) and the Islamic "da'wa system" for fortune-telling, the source of which Ifrah $(1998,261)$ attributes to Ibn Khaldūn. ${ }^{3}$ Somehow, perhaps by way of

\footnotetext{
3 The meaning of $d a^{\prime} w a$ seems unclear in this context, but is so cited in Ifrah (1998).
} 
anonymous rabbis and imams, it developed over the centuries, e.g., as kabbalah influenced the Italian Renaissance (see Percival 1984), and eventually (perhaps by way of Pico della Mirandola and Johann Reuchlin) appeared in Fabré d'Olivet's (1815) "hieroglyphic" theory of Hebrew grammar. (The term "hieroglyphic" was an apt one for the theory that a single orthographic symbol has a meaning - at least before the discovery of the actual meanings of the hieroglyphs!)

Admittedly, the literature on the meanings or "wisdom" of the letters is as distinct from structural linguistics as alchemy is from chemistry. For example, it relies not only on words and roots using a given letter (often but not necessarily as initial letter), but also insights derived from the name, shape, and numerical position of the letters - and freely derives homiletic advice from any or all of these. Within the (often large) set of meanings that are assigned to any letter, one can often find meanings close to the ones hypothesized in key-consonant theory. But certainly the principle of individual consonants having individual meanings can be logically traced to this literature-more closely, I propose, than to biconsonantal root theory.

Returning to the history, Fabré d'Olivet's grammar influenced a young Benjamin Whorf to study linguistics, with wide-reaching effects. Certainly Bolinger must have been influence by Whorf. It was Bolinger who proposed the existence of submorphemes, in particular assonances (initial clusters) such as \#gl- for "visual phenomenon" and rimes (vowels and finals), as having their individual meanings. Magnus later proposed that the meanings of the assonances are built out of the meanings of their constituent consonants, and thus arrived at a theory (for English and language in general) that is consistent with key-consonant theory, with one exception: I have found only the initial consonant to be semantically significant, and remain unconvinced by Magnus's analyses of non-initial consonants, whether in clusters or elsewhere. Thus, key-consonant theory of Semitic finds itself somewhere between the analyses of English suggested by Bolinger and Magnus.

Another partial truth, perhaps more a distraction than a help, is that of sound-symbolism (e.g. Hinton et al. 1994, Taylor \& Taylor 1965)which many modern analysts of submorpheme theory including Magnus reach to as an explanation for single consonants having meaning. (However, Gazov-Ginzberg 1965 proposes a sound-symbolic analysis of Semitic in which roots can have various numbers of consonants-often four.) While I do not at all deny sound symbolism as a possible distant source for key-consonants (and perhaps of language generally), I find it mostly irrelevant to the actual study of key-consonants. For one thing, 
key-consonants have mostly different meanings in different languages; for example, initial $\boldsymbol{p}$ means open in Hebrew, point in English, and smooth in Mandarin! It is interesting to consider sound-symbolism, but only after studying key-consonants in themselves.

In summary, it would seem fair to say that key-consonant theory represents a meeting point of biconsonantal root-theory, sound-symbolism, submorpheme theory, and the mystic theory of the "meanings of letters" as propounded by Ibn Sīnā, the Zohar, and various more recent authors. I leave for the reader to determine how much it derives, logically, from these earlier theories. To summarize the initial distinction from biconsonantal root theory with which I began this discussion: The key-consonant system goes beyond the 3-consonant and the 2-consonant root, although the distance and direction it goes in are different (especially where 2-consonant root theory concerns the reconstruction of proto-Semitic or proto-Afroasiatic).

In any case, all of this represents a logical or hypothetical history of the concept, not its actual genesis. In point of historical fact, it emerged from my attempt, some ten years ago, to create a convenient root-list for intermediate Hebrew students (and which recalled my efforts to do so for myself twenty years earlier). The insight that the initial consonant of a Hebrew root gives a crucial clue to the root's particular meaning (wherever this insight comes from) helped me to turn this draft dictionary into a key-letter lexicon of Hebrew (one version of which was the one-page dictionary), followed by exercises to teach the system to Hebrew students. As the booklets for learning the system have gone through revisions and different generations of Hebrews students, I have become more convinced of their practical as well as theoretical relevance-in advance of making the above logical connections, or finding out about the application of submorpheme theory to English.

My research on Arabic followed from wondering, more recently, whether it too might exhibit such a lexical structure. Root-dictionaries based on short word-lists were very unconvincing, but initial study of Wehr's Arabic dictionary quickly convinced me. Plowing through its 1000 pages during trips to the Middle and Far East resulted in a keyletter lexicon of Arabic that reminded me of my first draft of the Hebrew equivalent.

It is my belief that 'applied' considerations, if possible, offer the strongest possible (albeit informal) corroboration of the reality of keyconsonants. However, this corroboration apples directly only to Hebrew: For Arabic, as noted, I must so far infer from the comparative degree of coherence exhibited in the key-letter lexicons of the two languages. 
Over recent years, I have become more aware of analyses of submorphemes in English, including Magnus's uniconsonantal theory. Magnus (1999b, passim) herself claims no more than 50\% of the English lexicon (in fact far less, since she does not attempt to cover the whole lexicon, but only monomorphemic words) conforms to her claims. Even in English, I notice an occasional exercise in an ESL textbook, and one former ESL learner has confided that he invented his own analysis of keyconsonants in English to help him learn the forbiddingly large vocabulary of the language. I do not doubt that submorphemes and even keyconsonants have some psychological reality for the native speaker of English, although not necessarily a very pervasive or important reality.

Even my first draft of the Arabic key-consonant lexicon exhibited far more coherence than that. If it had remained as unwieldy as at that stage, I would have concluded that key-consonants, although a psychologically real characteristic of Arabic, are too diffuse a psychological phenomenon to be useful for students of Arabic as a foreign language. But a recent trip has allowed me to make a needed further revision, and I am now convinced that key-consonants are almost as "neat" in Arabic as in Hebrew.

Analogical Modeling and Submorphemes.

What is by far the most controversial aspect of the key-consonant system is its linguistic structure. For I will be suggesting, for example, that the initial $\boldsymbol{l}$ of Arabic lughah "language" is meaningful, that is, what we shall later call (following Bolinger 1965; see also Bolinger 1968) a submorpheme - while at the same time admitting that the residue or remainder of the word, -ughah, is not meaningful. Such a situation seems to contradict the intuition expressed in the traditional concept of the morpheme, according to which words can be segmented into "all and only" morphemes. Examples like lughah are far more disturbing than well-known potential counter-examples to segmentation like cranberry, since cran, as a whole syllable, "feels like" a morpheme, even if it happens to lack an independent meaning. (But even examples like cran- are more widespread than generally recognized, as examples like re-peat show. In fact, most examples are trickier than simple segmentation allows for, if we are honest.)

Although the segmentation of morphemes long predates the generative grammar of Noam Chomsky, I would suggest that Chomsky was expressing an older, indeed an ancient linguistic, insight or intuition of "generativity," which we can see as even pervading traditional Semitic linguistics. 
For example, insights about biconsonantal roots have long existed in Semitic linguistics (see especially Hurwitz 1966, a reprint from 1905, with many specifics; also Voigt 1988, Hodge 1977, and Ehret 1995). But the mainstream analysis of Semitic roots is rather straightforwardly (even dogmatically) triconsonantal, with biconsonantal insights all but completely absent in mainstream presentations, especially those intended for students.

I suggest that the (seeming) advantage of triconsonantal roots derives from essentially generative intuitions: the greater ease with which triconsonantal roots can serve as a basis for deriving the conjugational forms of verbs. This concept of generativity is called structuralism in Skousen (1989), suggesting its pervasiveness in modern linguistics - but, as noted, in Semitic linguistics it long precedes European structuralism. Biconsonantal roots, by the way, would qualify as submorphemes in the most relevant sense of leaving the third root-consonant as a remainder without independent meaning. The "startling" fact of "extensions" (Ehret's 1995 comment) being added to form triconsonantals from biconsonantals without apparent pattern or meaning of their own is the same as Bolinger noted for the remainder of the morpheme in submorpheme theory.

However, this generativity has been under attack in linguistic theory for decades. Skousen (all references) has been arguing specifically for analogical modeling as a preferable template for many or all linguistic structures. Such an approach overcomes such traditional problems of generative approaches as gaps in paradigms. While the details and broader implications of Skousen's theory go far beyond our present needs, it may be worthwhile to briefly demonstrate its significance with respect to the voices ("forms") of the Semitic verb. Semitic linguistics presents them with some hints at generativity, labeling specific voices as having "typically" intensive meaning or passive meaning, as well as giving "rules" for their conjugational forms, which are the main subject of grammatical expositions of the verb. Paradigm tables are also generative in the present sense, since they are given as examples for the whole system.

But it must be admitted sooner or later that the whole system is far from generative: Students must be warned against freely creating their own verbs on the basis of their meanings, because of the many semantic, syntactic, and inflectional gaps and irregularities in the system. (See Hassanein \& Abdou 1991, passim, for an impression and examples of the irregularity.)

Skousen's approach provides, I suggest, a less misleading presentation 
of the Semitic voices of verbs: Instead of focusing on overgeneralized (generative) rules for the formation and meanings of different voices, it would suggest the presentation of roots and their derived verbs in tables (not paradigms, but rather complete tables for all roots) to display the analogical relationships, along the lines of Hassanein \& Abdou (1991).

Of course this does not exclude use of paradigms and even generativelike principles as useful pedagogical insights, that is, as inaccurate but very handy initial generalizations in an incremented, articulated pedagogical system - a main feature of my general pedagogical system as well (bar-Lev 1994a, 1994b; Celce-Murcia 1991). The only limitation is that they should not be presented in such a way as to lead to ultimate disappointment, but not all initial overgeneralizations will lead to such disappointment. (I will return again to Semitic voices later in a pedagogical context, as a subsystem to compare with the key-consonant system.)

On a theoretical level, however, even inflectional paradigms, in Skousen's system, must be presented as complete tables (analogical models) rather than rules or even tables of paradigms, to capture their potential irregularity, as noted.

But submorphemes are just as naturally displayed in the same form, for example, Bolinger's table (selected examples shown here) for the submorpheme \#gl-, meaning (according to Bolinger) "visual phenomenon," with specific words conforming (left column), or partly conforming (middle column) or not conforming at all (right column). (See Table 2.)

$\begin{array}{lll}\text { Table 2. } & \text { The Submorpheme } \# \mathbf{g l} \text { - } & \text { (Abbreviated } \\ \text { VISUAL } & & \text { from Bolinger). } \\ \text { glance } & \text { glass } & \text { gladiator } \\ \text { glare } & \text { glamour } & \text { gland } \\ \text { gleam } & \text { gloat } & \text { glee } \\ \text { glimmer } & \text { glory } & \text { globe } \\ \text { glimpse } & & \\ \text { glitter } & & \\ \text { gloom } & & \end{array}$

The supposed "problem" of the remainder is simply not a problem in such a presentation; nor is the existence of non-conforming words. The relationships simply are as they are, as significant as their pervasiveness (or non-pervasiveness) may imply-available for native speakers to extend (overgeneralize) or restrict (undergeneralize) as they may. It is suggested by such a theory that a given native speaker may or may not un- 
derstand a new word with the same submorpheme, such as They saw the glinn at dusk and hurried home. Even a totally sporadic relationship might suddenly turn into a new submorpheme for one speaker or several, and might or might not evolve more fully.

Native speakers of English tend to imagine that splice means "split," where in fact it means "join, attach." This would seem to relate to the submorpheme spl-/spr- meaning "separate, spread" (split, spread, spray, splay, etc., including the abstracts spree, splendor). A possibly similar example is the semantic change whereby glamor diverges from its original meaning "grammar" along with its change from $g r$ - to $\boldsymbol{g l}$-. But this sort of data is hard to achieve, especially within a controlled experiment, nor can we claim that all historical "contaminations" will follow along neat lines.

Obviously such a theory of submorphemes is exemplified in the theory of Semitic biconsonantal roots. The question is no longer whether such submorphemes "exist," but whether they are pervasive enough to have real significance. (I will return to this issue several times below.)

But the present proposal, we should note, is a rigorously uniconsonantal theory of the root, albeit one applying to the synchronic structure of modern languages. It is important to emphasize this, since Semitic linguists familiar with biconsonantal theory (albeit as a non-mainstream insight) may think (especially because of the tendency to believe that "there is nothing new under the sun") of a uniconsonantal hypothesis as the very same, or at least more of the same. As noted earlier, it is true that one can arrive, in a conceptual sense, at uniconsonantal theory simply by "re-playing" the reasoning that takes one from triconsonantal theory to biconsonantal theory.

However, the "re-play" and the result are really completely different. No longer do we have a set of perhaps a few hundred biconsonantal roots covering some fraction of the language, but rather a theory in which, in principle, all individual initial consonants have meanings of their own. No longer do we have to admit that many roots are simply triconsonantal, but instead we see that the irregularities move to a completely different plane: There can no longer be any discussion of whether the remaining consonants have meanings of their own: The remainders (conforming, of course, to Bolinger's insight) are simply too large for this to be maintained; and the non-conformities move to the level of meaning variations in the specific initial consonants (again, no surprise: the meanings of any given initial consonant are simply multiple and complex, as indeed we might expect in analogical modeling - or indeed in any other serious theory of meaning in language). 
Insights in Older Literature.

The Sefer ha-zohar ('Book of splendor,' Bar Yohai 5758), mentioned earlier, contains a long section at the beginning on why bet, although the second letter of the Hebrew alphabet, was chosen to be the initial letter of the Torah, the answer being that it stands for barukh "blessed," with which blessings begin. Muslims may feel déjà-vu at this insight from the Zohar, since similar insights do occur in Islam for why $b \bar{a}^{\supset}$ begins the Koran. Similarly, I once heard an Islamic sermon, suggesting how the Arabic letter lām in Allāh shows the tongue rising towards God, which fits well into my analysis of Hebrew lamed, and certainly could apply to Hebrew Elohim "God"-although I don't know of a parallel insight in the literature for Hebrew. (Oddly enough, my analysis of lām will be quite different. As noted, no general accuracy is claimed for the mystic insights.)

For Hebrew, there are several modern books (Ginzburg 1995, Hoffman 1998, Lipiner 1989, Munk 1983), as well as the earlier references in Sefer bahir (Kaplan 1979) and the Zohar, already mentioned. So far I have found one full book on the subject in Arabic, Malik's (2000) Ayn al miftah, with one to several meanings given for each of the letters; also the reference (Lory 1996) to Ibn Sinnā's work on the subject, for which the reference gives meanings for five letters; a general discussion in Schimmel (1975); and the reference attributing the "da'wa system" to Ibn Khaldūn (Ifrah 1998, 261), which seems to fit into the general classification of "letter-magic" (simiy $\bar{a}^{\supset}$ ) following Ibn Khaldūn's classification (Ibn Khaldūn 1958). As mentioned earlier, Ibn Sīnā is apparently the first to have specifically posited individual meanings for Arabic or Hebrew letters. (Needless to say, I will be grateful for any references for this on-going research. $)^{4}$ Table 3 compares the three sources on Arabic.

Table 3. The Abjad in Sufism (Selected)

\begin{tabular}{|c|c|c|c|}
\hline \multirow{2}{*}{$\begin{array}{l}\text { Ibn Sīnā } \\
\text { the Creator }\end{array}$} & \multicolumn{2}{|c|}{$d a^{c} w a$ system } & \multirow{2}{*}{$\begin{array}{l}\text { Malik } \\
\text { Allah, first, last }\end{array}$} \\
\hline & Allāh & Allah & \\
\hline $\begin{array}{l}\text { Intellect vis-à- } \\
\text { vis Light }\end{array}$ & $\boldsymbol{b} \bar{a} q \bar{\imath}$ & $\begin{array}{l}\text { He who re- } \\
\text { mains }\end{array}$ & house, in, blessing, creation \\
\hline Initiation; Order & $\boldsymbol{h} \bar{a} d \bar{\imath}$ & Guide & guidance \\
\hline
\end{tabular}

\footnotetext{
${ }^{4}$ I am grateful to Barbara Jurgens of the Golden Sufi Center, and Sara Sviri of University College London, for helpful suggestions in tracking down some of this literature; to Khalid Malik for additional insights cited below; and to Stan Tenen of the Meru Foundation for directing me to the Ifrah reference.
} 


\begin{tabular}{|c|c|c|c|}
\hline $\begin{array}{l}\text { Intellect vis-à- } \\
\text { vis Soul }\end{array}$ & $\boldsymbol{w} \bar{a} l \bar{l}$ & Master & $\begin{array}{l}\text { love }(\boldsymbol{w} u d \bar{u} d), \text { intercessor, } \\
\text { time }\end{array}$ \\
\hline Creation & $z \bar{a} k \bar{\imath}$ & Purifier & pair \\
\hline Generation & Haqq & Truth & $\begin{array}{l}\text { praise, letter, veil, wisdom, } \\
\text { living }\end{array}$ \\
\hline
\end{tabular}

But what a strange literature this is, whether for Hebrew or Arabic! For English (or French or German, or Greek, Russian, Georgian, Armenian, Thai, Japanese kana, and others), I have not seen books on the "meanings" or "wisdom" of the letters. To be sure, there are many books that give sample words beginning with the letters, mostly as a way for children to learn the letters. But this is quite far from any implicit claim or suggestion that these are "meanings" of the letters: zebra and zoo begin with $z$, but they are not suggested to represent the actual meaning of this letter in any book that I have ever seen (tempting as it might be to do so, in this example). In fact, it is generally obvious to linguists (and perhaps everyone else) in all these languages that letters don't have meanings at all, except when combined in words. (The hypothesis of submorphemes, of course, takes a radically different view, although still only partial.)

In Hebrew and Arabic, there is thus a long tradition suggesting that individual letters do have their own meanings, at least in some sense. I suggest, then, that the mystic literature about the Hebrew and Arabic alphabets does offer potential and indirect intuitive support-much as consonantal alphabets and the general focus on letters in traditional Semitic grammar hint at the importance of consonants in these languages-for the existence of submorphemes in these languages, and indeed, more specifically, submorphemes of a single consonant. It is even possible that individual insights about specific consonants may have some linguistic truth, although the proof for any intuition, of course, must come from analysis of the languages themselves. The insights are in any case so varied that they cannot all be true! Apparently the letters serve as a kind of Rorschach drawing, helping the mystic to draw out subconscious ideas. In both traditions, it is clear that the "meaning" of a given letter can be found in (1) its numerical order (in Arabic, in either of the two alphabetic orders), (2) its shape, (3) words that contain it (at the middle or end of the root), and/or (4) words that begin with it. It is this last connection (4) alone-words that begin with the letter-that is specifically supportive of the present discussion. (For Arabic, see Malik (2000) and Schimmel (1975) for specific examples and discussion.)

But let us note parenthetically that considerations (1-2), the shape and order of the letters, can occasionally be supportive of (4), words begin- 
ning with the letter. Indeed, for Hebrew, I long ago concluded that the letters in square Rabbinic script can be regarded as illustrations of the meanings (e.g., samekh, shaped as a circle, with key-meanings spin and complete), and argued (in bar-Lev 1999b) that this was a reason for the choice of this script over the older "Old-Hebrew/Phoenician" script. Most analyses of Hebrew bet, the second letter, hint at a meaning of "duality" on the basis of its order, which can be claimed for its shape (with higher and lower bars) and roots that begin with it, such as $b-y-n, b-d-l$, $b$ - $g$ - $d$ "between, divide, betray" and many others. (I will need a little more research to even begin considering the parallel question for Arabic - but some similar insights have appeared possible, by first impression.)

Consideration (3) - words containing the letter internally-actually seems to undermine or at least not support the present perspective. Indeed, the higher prevalence of (3) in Sufi literature, as against kabbalah, might make us initially more skeptical of the applicability of key-letter theory to Arabic. However, Malik [personal communication] states a position far closer to the key-letter interpretation, namely that "Each letter is special. In abjad interpretation they [the letters] are regarded equally, [but] in spiritual interpretation there is a hierarchy. The chain of command is that the first letter [of a root] controls the one after, and the one after controls the one after that." A similar question will be relevant when we consider below whether English exhibits a parallel system.

\section{The Alphabet in Lexicon and Learning.}

Let us now discuss the linguistic and psychological issue, considering key-consonant theory as a solution to the lexical problem in linguistics. The lexicon of any language is extremely large-so much so that it is something of a theoretical or psychological mystery how native speakers ever master it well enough to use the language. In reading, the mystery is particularly great: If "ordinary educated" native speakers have an average comprehension vocabulary of 40,000 words (as I estimate on the basis of informal research with my students, as well as the study by Nation 1990), how do native speakers acquire and retain them-and, practically more important, how can non-native speakers ever learn to use the language?

For foreign learners of Hebrew and Arabic, the root-structure of the language helps considerably. This in spite of its irregularity, which is of course disconcerting to foreign students, not to mention its abstractness. But by overcoming the natural resistance to learning new concepts, students can reduce the need for memory, learning one root instead of two 
words for "brother/sister," "see/show," "come/bring," or hundreds of similar pairs, triplets, and the like, for both languages.

Of course students must overcome the more general misconception that words correspond one-to-one across languages. Sometimes this crucial insight causes great emotional difficulty. But students must master this insight anyway, in order to deal with any text, since the words in one language always do have multiple meanings (or at least multiple translations): Students who cannot "deal with" this concept will probably never function independently in the language - even if they may thrive in mainstream courses. Even if the student would prefer a simple correspondence between languages, at least the existence of helpful concepts like the root ultimately more than compensates for any intellectual challenge. As I like to tell my students: Your head is easier to carry than a dictionary - and there is less danger of leaving it home. But students are not always easily convinced.

Metaphoric extension is particularly crucial. A foreign learner who can never accept that, for example, Semitic "head" can also have a metaphoric meaning of "beginning" ( $\mathrm{ra}^{\mathrm{s}} \mathrm{s}$ as-sana "head of the year") and also "leadership" ( $r a^{s} \bar{\imath} s$ "director, reader") - although only the second of these exists in English - will be unable to go very far in Arabic.

I suggest, by the way, that Bolinger's analysis of \#gl- as "visual phenomenon" means "flash," with glance meaning "flash a look." (This analysis moves glass, glory, and glee into the submorpheme-but moves gloom out.) Similarly, English splendor, spree fits with the submorpheme spl-/spr- as in spread, spray, splay, split, etc., as a metaphoric extension.

Syntactic extension is another problem, especially in Semitic, especially in voices of the verb: It is not easy for an American to understand Arabic "show" as meaning "cause to see," or especially "teach" as "cause to learn" (especially when there is another expected meaning, "know intensely").

But, however much root study may be helpful, the number of roots in a Semitic language is still quite large, and it is possible to study the language for many years and still not learn all of the roots that occur in ordinary texts. It remains far easier for an American, in particular, to read Spanish, with its thousands of cognates, than Hebrew or Arabic, with few cognates, even these being recognizable only with difficulty. The comparison is relevant, furthermore, because for American students at least, the choice, when fulfilling a language requirement, is indeed between Spanish and harder languages.

Moreover, the roots create a problem of their own, in that one cannot 
look up words in a dictionary in the form that one finds them in. Prefixes for "the" and prepositions and conjunctions, apart from conjugational prefixes and especially "infixes", additionally make words far less "transparent" for the Arabic dictionary user than in Spanish. While the problem of dictionary look-up is quite severe simply because of prefixes and infixes, it becomes even worse when the dictionary is arranged by roots (as in most Arabic, and in older Hebrew dictionaries).

\section{ARABIC KEY-CONSONANTS.}

\section{Current Analysis}

Let us turn now to the specific analysis of Arabic. A first set of entries for one initial consonant, namely $\# \boldsymbol{l}-$, is given in tables four through eight. The five main meanings, in my latest draft, are derived from the assumed primary meaning, cling, as shown by arrows in the chart: cling $\rightarrow$ connect, cling $\rightarrow$ gather, cling $\rightarrow$ tongue, cling $\rightarrow$ tongue $\rightarrow$ negative. The individual roots vary in tightness of fit with their assigned main meaning, just as the tightness of connection between meanings varies.

The most mysterious is probably negative, derived from tongue. Some may be especially skeptical about the connection between the full negative words ("destroy, abridge, crush, ...") and the particles ("no, not, but, if"), but I have found literally all Hebrew particles and prefixes as well as function words to be derived from meanings of key-consonants; similarly in Arabic $l i$ - and ila "to" clearly fit with "cling, attach" as a meaning of \#l-, and $l-z-m$ "must" is easily analyzed as a metaphoric extension of "cling." I have no idea whether most or all particle and affixes in Indo-European languages are derived from full words (in English, auxiliaries do come from full words, e.g., the auxiliary will originally meaning "want"), but this has seemed to be the case in Semitic, in my research.

It may be more generally noted that some of the tongue words are negative in meaning, and some of the negative words involve speaking. Readers may well be skeptical of individual entries: If so, they may try highlighting the ones that seem convincing to them - and recalling that these are essentially all of the roots in Wehr's dictionary (except those under soft).

Metaphoric extension may not seem exactly the right term-but I suggest that most or all the adjacent meanings seem to be fairly natural semantic extensions of some kind. "Closeness" is naturally associated with "clinging"; indeed, "closeness" is also found as a variant of "cling" within several roots; further, "clinging" is a natural function of the 
"tongue" or "mouth"- although, to be sure, this is a metaphoric connection that may surprise a learner whose native language is American English: I doubt that most Arabic-speakers would be so surprised.

Expanded roots, e.g., with initial alif such as ilāh/Allāh "god/God," and ila "towards" are included, under the assumption that alif (or hamza) is not a key-consonant. (In Hebrew, six consonants-all of them "weak," including $\boldsymbol{n}$-are non-key. The status of the corresponding consonants in Arabic needs further research.)

These tables leave unsolved the question of polysemy. Sometimes various meanings of a single root are related interestingly, such as: $l-h-n$ as "compose" and "speak badly," as well as $l-z-m$ as "cling" and "must." The second represents a metaphoric extension - with an abstract, more or less grammatical meaning "must" derived from a concrete meaning "cling"; the first exemplifies approximate opposites - hardly unusual or surprising. Of course a complete solution to polysemy is not offered here (or anywhere else), but must await far more understanding of lexicon in general. What we are proposing here is to approach this whole problem from an entirely different starting point than the usual cataloguing.

We might mention two English examples, such as park a car vs. the city park. Are these two different words that happen to sound the same (homonyms), or are they two different and perhaps even related meanings of a single word (polysemy)? The same for ear (on the head) vs. ear of corn. (This is not a question of historical but structural-psychological relationship: Historically, the two words park are related, the two words ear are not.) If two different words, are they nevertheless closely related? My native speaker's intuition tends to this conclusion. In the first example, it may be impossible to guess one meaning from the other, even in context, but seeing a connection between them might make learning them easier to learn-for the native speaker as well as the foreign learner.

Let us especially note that a more common meaning of a root is not necessarily the primary one, as in the root $l-h-m$ "meat," which is less clearly related to the key-meaning than the more unusual "patch" (just as with $l-z-m$ ) - but it is often the case that the "deeper" meaning of a word may be learned later by a native speaker: An American child might well learn television before learning vision (much less tele-); native speakers of English invariably learn just one kind of trolley, usually without knowing the actual meaning of the word itself.

\section{Key-Meanings for \#l-}

The key meanings of $\# l-$ can be outlined as follows: 


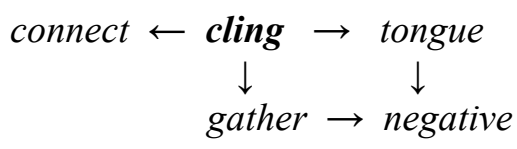

We can see examples of these in the following tables.

\section{Table 4. \#l-.Cling}

\begin{tabular}{|c|c|}
\hline stick, cling & \\
\hline cling; council & جن \\
\hline towards & \\
\hline adhere & \\
\hline fixed, attached & \\
\hline dispute, bewildered & \\
\hline
\end{tabular}

\begin{tabular}{|c|c|c|}
\hline cling; must & لز لزم & dense, close \\
\hline cover, wrap & & in presence of \\
\hline to & & to stick; next to \\
\hline cover, wrap & لحف & close; request \\
\hline roll up & ف & adhere \\
\hline wrap, wear, obscure & لبس لبس & cling \\
\hline tie & & god, God \\
\hline
\end{tabular}

Table 5. \#l- Cling $\rightarrow$ Connect

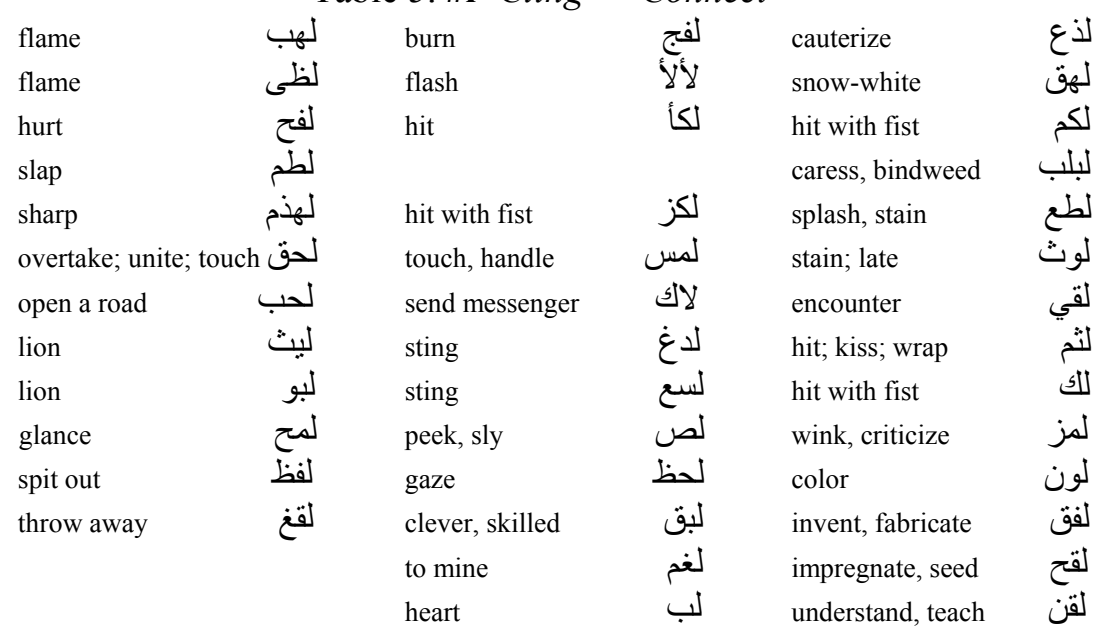

Table 6. \#l- Cling $\rightarrow$ Gather

\begin{tabular}{|c|c|c|c|c|}
\hline gather & لقط & rob; secretly & لص & penitentiary \\
\hline gather up & لملم & bandage & لاعم & linger \\
\hline gather; calamity & لم & refuge & لجأ & restrain \\
\hline gather, collect & لقط & refuge & لوذ لوذ & stubborn; depth \\
\hline
\end{tabular}

Table 7. \#l- Cling $\rightarrow$ Tongue

\begin{tabular}{|c|c|c|c|c|c|}
\hline tongue; eloquent & لسن & lick & لعق ل لعق & to name & لقب \\
\hline suck, milk; brick & لبن & to pant & لهث & babble; stork & لقلق \\
\hline lick lips; backbite & لمظ & speak; nonsense & لذا & bite; obstruct & \\
\hline chew & لف & chew & لوك & comnose. sner & لحن y y y y y y \\
\hline
\end{tabular}




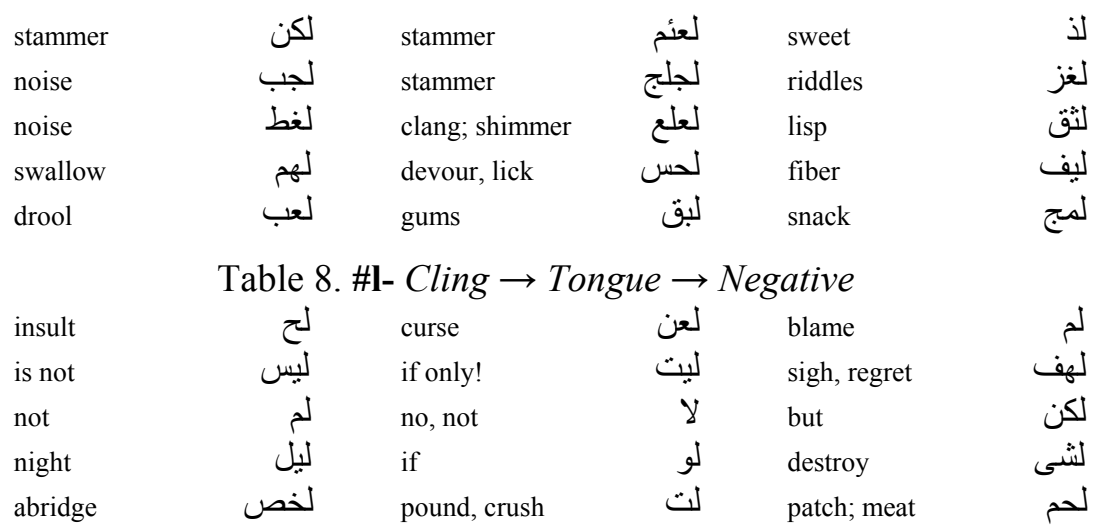

A key-consonant lexicon is more useful for many pedagogical purposes than a regular dictionary: While the lack of internal organization is a disadvantage in locating roots, it is offset by the need to flip pages in a regular dictionary. A key-consonant lexicon is best for learning, not reference: It becomes unwieldy if it includes all meanings of every root. The sample given here is probably far too large for even a third-semester course.

An even more interesting pedagogical device made possible by keyconsonant theory is the one-page dictionary, in which the roots are not listed at all. Instead, each key-consonant is given with an outline of its main meanings, and various common meanings of individual roots. Needless to say, students must practice using such a one-page dictionary: No one (including the author) would be able to make the semantic leaps needed without explanation and practice. (Thus it does not lend itself to immediate controlled experiments.) On the other hand, such a one-page dictionary represents what we would like students to know of keyconsonant theory.

It is a handy device, especially during the time in which incremented pedagogical exercises are not yet written. As I am learning by teaching the key-letter system in Hebrew, it must be presented in increments, for example, for lām, focusing on the meanings more obviously related to "cling" in the second semester, leaving other roots that occur as exceptions, and then adding other meanings that cover these exceptions in the third semester. Abundant exercises must be presented, so that students get the feel for how far they should deal with particular meanings - apart from the importance of repetition; frequent quizzes are needed to ensure command of the basics. The importance of instant ("fluent") command of basic meanings should not be underestimated: Subtleties of the system can be appreciated, but not used, if students are not in total command of 
the basics. (But I should emphasize again that the pedagogical applications are proposed here not only for themselves, but also for their descriptive-theoretical implications, supporting as they do the reality of key-consonants.)

Key-Meanings for \#k-

As a further example, I present my current analysis of \#k- in the following tables (dark $\leftarrow$ cover $\rightarrow$ collect $\rightarrow$ push $\rightarrow$ control $\rightarrow$ measure). Five roots in one meaning-group, push, are omitted for considerations of space. Seven roots with this key-letter remain unclassified.

\begin{tabular}{|c|c|c|c|c|c|}
\hline $\begin{array}{l}\text { cover, atone; } \\
\text { atheist; village }\end{array}$ & كفر & headdress & كفي & hood; suppress & كبت \\
\hline cover & 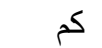 & lime & كلس & armor & كمى \\
\hline linen & كتن & clothing & كس & protect & كنف \\
\hline shroud & كفن & $\operatorname{dig}$ & كرا & bury; firm & كنز \\
\hline shoe & كندر & feed, support & كفد & crown & اكلل \\
\hline stay home & كنكن & cave & كهق & monk cell & كرح \\
\hline hide; cumin & كمن & hide, refuge; cherry & كرز & hut & \\
\hline conceal & كرز & sleep; rest/rent? & كرى & hide & كتم \\
\hline conceal & كظم & deceive & كد & pantry & 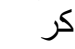 \\
\hline blind & كمه & deceive & كذب & & \\
\hline \multicolumn{6}{|c|}{ Table 10. \#k-Cover $\rightarrow$ Dark } \\
\hline lazy & 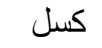 & sweep; lame & كسح & stumble & 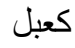 \\
\hline dark & كفهد & sad, dark & كمد & wear out, dull & كل \\
\hline wrinkled; potbelly & كرش & dry, shrivel & كز & muddy, dreary & كدر \\
\hline wrinkle & 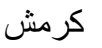 & dirty & 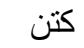 & fall forward; dull & كبا \\
\hline sad & كئد & grief & كئب & distress & 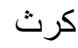 \\
\hline stagnant & 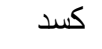 & frown, austere & كمد & callus & 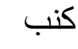 \\
\hline \multicolumn{6}{|c|}{ Table 11. \#k- Cover $\rightarrow$ Collect } \\
\hline group; constellation & 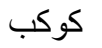 & pile up & 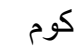 & crowd & كوف \\
\hline thick, dense & كثف & thick, dense & كثث & fertility, abundance & 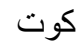 \\
\hline much & كثر & pile up & 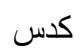 & great, large & كبر \\
\hline overfill & 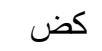 & overfill & كظ & & \\
\hline earn & 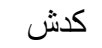 & win & 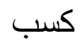 & livelihood; form; tax & كسم \\
\hline $\begin{array}{l}\text { whole, finish } \\
\text { perfect }\end{array}$ & كمل & all; college & كل & $\begin{array}{l}\text { palm; all, enough; } \\
\text { edge; blind }\end{array}$ & كف \\
\hline gather, lump & 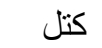 & quarantine & 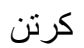 & crowd & كردس \\
\hline ball & كر & & & collection & كنش \\
\hline roll up; furnace & كور & lump, ball & كبتل & bag; clever & كيس \\
\hline
\end{tabular}




\begin{tabular}{|c|c|c|c|c|}
\hline tumble; ball, tumbler & كب & cup & كأس & cup \\
\hline jug, mug & كوز & restrain; meatball & كفت & guard, keep \\
\hline
\end{tabular}

Table 12. \#k- Cover $\rightarrow$ Collect $\rightarrow$ Push

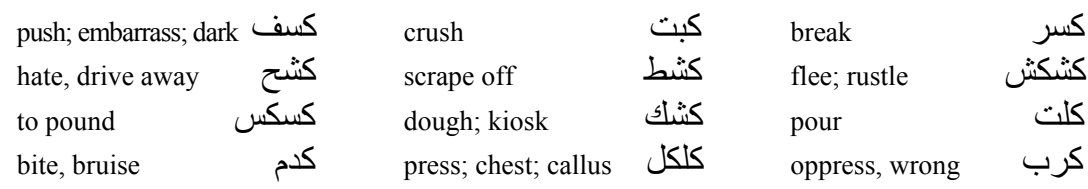

Table 13. \#k- Cover $\rightarrow$ Collect $\rightarrow$ Push $\rightarrow$ Control

\begin{tabular}{|c|c|c|c|c|c|}
\hline control & كبح & grasp; ram & كبش & tongs; dog & كلب \\
\hline seize; shrink & كمش & hold back & كفكف & shackle & 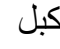 \\
\hline manacles & كلبش & hold back & كمت & knot & كعبر كبر ك ك ك \\
\hline electricity & كهرب & & & muzzle & \\
\hline & كرط & intelligent & كوس & muzzle & كم \\
\hline cream; vine; & كرم & paint eyes; blue, kohl & كحل 1 & smart, pretty & 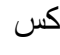 \\
\hline
\end{tabular}

\begin{tabular}{|c|c|c|c|c|c|}
\hline speak; injure & كلم & surname; allusion & كنا & $\begin{array}{l}\mathrm{drOl} \rightarrow \text { Measur } \\
\text { predict, priest; rag }\end{array}$ & كهن \\
\hline quantity & كم & condition & كيف & almost & كد \\
\hline turn over, ball & كب & be & كون & repeat & 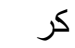 \\
\hline so that & 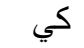 & like, as & 5 & vice- & كه \\
\hline $\begin{array}{l}\text { probe, essence } \\
\text { extreme }\end{array}$ & كن & $\begin{array}{l}\text { liver; middle } \\
\text { inflict; wear out }\end{array}$ & كبد & kidney & كلي \\
\hline church & كنس ك & work & كار & workshop; brothel & كركن \\
\hline & & exert oneself & كدح & work hard & كد \\
\hline measure; kilo & 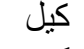 & & & butler & كرس \\
\hline kilo (abbrev.) & كغم & chemistry & كيميياء & $\begin{array}{l}\text { chair;cohere } \\
\text { notebook; foundation }\end{array}$ & كرس \\
\hline elbow & كوع & wrist & كسع - (ك & write & كتب \\
\hline
\end{tabular}

Prospects for Further Revision.

In reviewing $\# \boldsymbol{l}$ - for the first draft of this article, I reduced thirteen basic meanings to ten, and finally, in my more recent overhaul of the lexicon, to the six now assumed, and I have similarly revised other consonants. In Hebrew, this was the most difficult stage of the research, but it ultimately reduced a similar complexity to just one to six basic meanings for each key-consonant, with obvious relationships between most of these, so that each Hebrew key-consonant is now assigned a single "original" meaning, and one major "derived" meaning, with (almost) all others deriving naturally from these.

I cannot at this point speculate about whether Arabic will exhibit 
similar coherence-much less whether Semiticists (as contrasted with students) will find it convincing! But let me insert here a brief impressionistic note, based on my research experience, further comparing Arabic with Hebrew, which I had reduced to a pedagogical system well before beginning to investigate whether such a system exists in Arabic. Since the primary stock of Hebrew roots is recorded in the Hebrew Bible, which is therefore more conservative than Arabic in this regard, I wondered, before investigating Arabic, whether the key-consonant system of ancient Semitic might have disappeared in Arabic - or perhaps would exist only in historical relics.

While, as expected, many of the connections in Arabic parallel those of Hebrew more or less directly, many of them do not. Hebrew and Arabic do share the meaning "tongue, speak" for lamed/lam - as not only in lashon/lisān "tongue" but also Arabic lughah "language," which does not exist in Hebrew. But $\# \boldsymbol{l}$ - also has many roots with meanings of "clinging" ("adhere, stick, cling") that do not exist at all in Hebrew. The systems seem clearly related historically, but quite different in specifics. (I am enough of a neo-Whorfian to wonder whether there is a difference in the meaning of Elohim vs. Allāh "God" relating to the difference between the primary meanings of their shared key-consonant: cling, adhere in Arabic vs. strive towards in Hebrew. This suggestion differs from that of the sermon mentioned earlier.)

A stark example of the difference between the languages is which consonants are not key-consonants at all. In Hebrew, I have hypothesized that alef, ayin, nun, he, vav, yud are not key-consonants: This hypothesis allowed for more successful groupings of large numbers of words. In Arabic, however, I have not found similar reasons to exclude, for example, \#n-. This is no doubt be related to the fact that Hebrew $\boldsymbol{n}$ is a weak consonant, which disappears in many forms of many words: If it had a key-consonant meaning in Proto-Semitic, it would be expected for it to disappear in Hebrew: For some roots, the original \#n- has disappeared altogether within the language, and is recoverable only through comparative reconstruction, implying that it no longer exists synchronically: There are simply no forms in Hebrew that would allow the native speaker to recover the missing consonant. I do speculate, on the basis of some examples looked at (such as ila and iläh/Allāh, that alif is not a key-consonant at all in Arabic, as in Hebrew, but ${ }^{c}$ ayn seems to have meaning - although I hesitate to hypothesize which of its various meanings is primary or "original" at this point in my research. (The analysis of alef/alif is interesting also with respect to some mystic speculation about the "meanings" of alef/alif, which are consistent with it being in- 
herently meaningless, as in Hebrew, where it gives rise to the richest mystic speculation.)

Practically speaking, it may not seem to be of tremendous value for there to be as many as five to seven key-meanings per consonant. But five to seven meanings per consonant is hardly complex as a hypothesis for organization of the lexicon in L1. This suggests a possible and partial solution for the lexical problem in L1 acquisition, as claimed, at least in Semitic languages. Even for L2 learning, the whole system would seem to offer an interesting possible antidote to those traditional teaching methods that require students to learn (as in one example known to me) 100 new words per week, which, in my experience with graduates from such programs, leads to massive confusion between words, as well as massive discouragement and attrition. Of course it may also turn out that there are fewer meanings than this in Arabic, as I eventually found to be the case in Hebrew.

One of the sillier reactions that I have gotten to my work on Arabic is that it includes roots that are little used: In fact, my key-consonant lexicon of Arabic contains almost all roots in the Wehr dictionary-surely not a defect in the research! However, I have been investigating whether an abridged list of roots might lead me to different conclusions. A first abridgement did in fact give a much smaller list of submeanings per consonant, suggesting that this would be a fruitful line for further, more systematic research. But I prefer to leave this possibility on the side, for two reasons: (1) it would be foolish to do such a large-scale revision without very solid and exact knowledge of the frequency of individual roots (Landau 1959 might be a useful tool, although both complex and in some ways limited in its corpus), and (2) the practical value of a keyletter lexicon is highest when it includes more; indeed its value comes from its ability to help with rare roots more efficiently than a regular dictionary can.

Whatever the answers to these further questions, even if further research does not further simplify the analysis of Arabic, it is already quite close to the coherence that I have found in Hebrew.

One of the more interesting aspects of the key-consonant system is the way in which it expresses relationships between key-consonants. In Hebrew, the key-consonants are naturally displayed in a single keyconsonant table; in this table, consonants mostly line up according to their meanings adjacent to other consonants of similar phonological character: the gutturals all together; $\boldsymbol{z}$ and $\boldsymbol{c} / \mathbf{s}(\boldsymbol{t s})$ together, although $\boldsymbol{s}$ and $\boldsymbol{s h} / \boldsymbol{s}$ are isolated elsewhere; $\boldsymbol{p}, \boldsymbol{b}, \boldsymbol{d}, \boldsymbol{r}, \boldsymbol{l}$ all together. In other words, they are partly (but only partly) related to phonetic relationships - and they 
are definitely language-specific. (Such a table expresses part, but not all, of the alternations captured in Bohas's theory.) It is too soon to formulate such a table for Arabic, although some parts of it have been fairly clear from the first draft of the key-letter lexicon to its more recent revisions. Interestingly, for example, $\boldsymbol{q}$ and $\boldsymbol{k}$; and also $\boldsymbol{f}$ and $\boldsymbol{b}$; but likewise $\boldsymbol{r}$ and $\boldsymbol{z}$; and equally $\boldsymbol{k}$ and $\boldsymbol{l}$-seem similar and therefore adjacent. (There may be a partial correlation, as in Hebrew, with letter-shapes, most interestingly in the case of $\boldsymbol{r}$ and $\boldsymbol{z}$ and also $\boldsymbol{k}$ and $\boldsymbol{l}$.)

\section{More on Validation}

To what extent can the claim of key-consonants in Arabic be regarded as validated? My view is that we are far from being able to validate very many interesting claims about lexical semantics, now or in the near future - largely because of the absence of an available set of semantic features, analogous to the phonological features used in phonological theory. How can we know whether, for example, "cling" and "must" are related meanings, as I have claimed? I think the case is intuitively obvious, but I have no idea how this might be expressed formally enough to be validated in any quantitative way.

Many of the semantic connections between roots of a single keyconsonant-like many of the different meanings of individual lexical items in any language! - are metaphoric extensions, of sorts that are not likely to be related to specific inferences or the like, much less to the kinds of semantic features ( \pm animate, \pm male, \pm directional, etc.) that are featured in mainstream lexical-semantic analyses. And yet they are clearly a reality in language: Metaphoric extensions are a pervasive part of lexical history, and new ones are created continuously.

We can again usefully compare the system with the much used system of voices ("forms") in Semitic. Obviously, this system has a certain usefulness in word-for-word translation; in some individual instances it is indispensable. It is not as clear, however, that it fulfills its promise in the classroom, much less lives up to the frequent teacher comment that this feature makes Arabic or Hebrew "more logical" than other languages: Some students seem so weak with voices that the system is clearly beyond their independent use of it.

In any case, I have found the system of voices to be far outpaced by the key-consonant system in general usefulness. That is, the key-consonant system applies in a far larger number of cases, and is more easily applied by a wider range of students. The very systematicity of the voices (partial as it is), I suggest, opposes its effective application, while the very randomness of the key-consonant system supports its use-al- 
beit perhaps not in the traditional classroom, in which word-for-word parsing predominates over the "psycholinguistic guessing game" (Smith 1971, 1973) that constitutes more realistic reading. The Semitic voices are systematic, but in a very complicated way; for example, students are invariably confused by the causative use of the intensive voice (e.g., "allam "teach" from "alim "know," as against kassar "shatter" from kasar "break"), as well as the complexities in the forms and syntax of the voices themselves. It is also frustrating when a student recognizes a voice but happens to land on the wrong meaning for the given context.

The various key-consonant meanings, however, are far less predictable, a far more complex case of scattered "analogies" (partial, varied relationships). This may seem like a disadvantage - but only when reading is regarded as decoding and translating; it works well when reading is properly regarded as a psycholinguistic process of hypothesis-making (i.e. the psycholinguistic guessing game of Smith), and students can actually deal with metaphoric extension, polysemy, and, for that matter, content and implications. There is a playfulness in this authentic readingprocess - and it is the same playfulness that is required for use of the key-consonant system. I cannot say that all students adjust to this play easily: Some of the best students, with the most outside background, resist it the most. But at least the goal must be clarified for all students as a matter of realism (authentic language-skill). Meanwhile, even the strongest "parsers" admit that they would rather acquire the needed flexibility than endlessly memorize arbitrary roots and meanings, or pick at individual word-forms to the extent that parsing requires.

It is more generally true that many students think that grammatical sophistication is needed for language study - even though fewer students every year seem to have the patience or actual ability to master it. I suggest that students can either share depressing nostalgic moments with their teachers - or together move on to a new way of learning language altogether, one which they might actually be good at. Over some ten years of teaching Hebrew students to read new material without any use of glossaries and dictionaries, I have finally found a set of classroom procedures that teaches students to guess unknown words freely and comfortably. (I do not confirm or correct their guesses until they have finished cooperative word-for-word translation on their own.) Once these procedures are in place, then key-letters can come into play equally freely; on this level, I find the key-consonant system to be more and more applicable, allowing students to guess meanings correctly most of the time.

Apart from guessing roots in context, it also follows from key-conso- 
nant theory (indeed it is the first and most important point), in Hebrew and Arabic, that roots are best learned with special attention to their initial consonant. In English such a strategy offers little benefit, since words beginning with a given consonant generally have no meanings in common-except for certain initial submorphemes, like $\boldsymbol{g l}$ - and $\mathbf{s p l}$-/spr-, which are, however, seem to be too few to be of use to the foreign learner. (See further discussion of English below.) But in Hebrew or Arabic, the shared characteristics of the meanings of roots beginning with the same consonant offer a special benefit for learning. Indeed, as noted, it has been surprising to me, as I plow through a Hebrew or Arabic dictionary in my research, that this fact of these languages seems to not have been noticed for its theoretical or pedagogical relevance (except perhaps, as noted, by heterodox grammarians and mystics): After reading just four to five pages of almost any consonant, the repetitions become obvious to me in either language. I get no such feeling looking through pages of dictionaries of English, French, Russian, or other languages. I suggest that this insight itself offers general validation for key-consonant theory: A student-composed "root-dictionary," or a key-consonant dictionary displaying words by meaning group (like the sample pages, but abbreviated for level), highlights roots by meaning groups. Can there really be doubt that such a study-technique helps students?

In contrast, my sense of English, French, Russian, and other languages, is that when a new word resembles a familiar one, it usually does not have a related meaning (unless it has a morpheme in common). For example, if a student of Russian knew korol" "king" and korabl" "ship" and saw a new word koren', I would suggest as a general strategy to assume that it has a completely different meaning, not a similar one. Guessing that it means something similar to a similar sounding word seems like a generally bad strategy. (Koren' means "root.") But psychologically, does the tendency for students to make such guesses not suggest that such connections are natural—even if perhaps broadly utilized only in Semitic languages?

To take one example from my perusal of an Arabic dictionary (Wehr 1976, 122ff.): jazz "to cut off..."; jaza "to divide, ..."; jazar "to slaughter, ..."; jazic "break apart"; jazam "cut off"; jarad "to peel"; jadhar "uproot"; jadham "cut off," ...; and numbers of other roots. Some of these roots share the first two consonants, but in general the biconsonantal root, perhaps because of its historical basis, is extremely complex, and pedagogically not very helpful. By "upping the ante" to the first consonant alone, the key-consonant system in fact isolates a system that is more abstract, to be sure, but also more regular, and far easier to use. 
The reason for this is that it brings the entire lexicon under a single theory, where, instead of perhaps a few hundred biconsonantal roots covering some fraction of the lexicon, a very small number of meanings per consonant cover the whole language.

Key-Consonants in English.

Let me finally return, as promised above, to the question of whether a similar system exists in English. The most ambitious attempt in this regard is that of Margaret Magnus (1999a, 1999b). Let me first say that I find her hypotheses brilliant, as well as quite probably descriptively correct to some extent. Individual insights, such as the semantic connections between words with initial $\boldsymbol{b}$ in bubble, burst, break, blow, bun, breast, bread, bud, back, and the like, are inevitably haunting, as more and more examples present themselves. Her hypothesis, in particular, that individual consonants have their individual meanings, is similar to my keyconsonant hypothesis - but hers is extended to every occurrence of every consonant, where mine is limited to the initial consonant.

I have certain doubts about Magnus's method. But, more to the point, I find her system far more abstract than I have found for Hebrew and Arabic. For $\boldsymbol{g}$ in give and get, for example, to represent "motion to or from a void," does not seem to me as helpful to prospective L2 learners, and seems forced as an analysis of English as such. Even the many apparent opposites in Semitic do not seem parallel to this example (e.g., the "tongue" meaning of $\# \boldsymbol{l}$ - meaning "eloquence" on one hand, and "stammering" on the other, an insight that seems to have far more semantic coherence and to give far more useful specificity than give vs. get). Her outline of $\boldsymbol{t}$ (the only phoneme that she surveys this way in Magnus 1999b, passim) gives seven different meanings, some related-but then she states that these account for only a third of the monomorphemic English words in her vocabulary. In other cases, she states that the generalizations cover up to $50 \%$. In my most complex key-consonants in Arabic, in the most recent version, there may be as many as seven to ten separate meanings, but most are related along themselves, and they account, in my system, for a minimum of $75 \%$ of the roots of any keyconsonant in Wehr.

But the biggest difference between Magnus's analysis of English and my analysis of Semitic is, as noted, that she includes all consonants in her claims, no matter where in the word they occur. These claims occasionally work for individual English examples, but I have not yet been tempted to pursue this possibility for Semitic. (Malik's intuition would imply, at least, that the first consonant predominates, even if the others 
contribute as well.)

Let's try it on some examples mentioned: Does $\boldsymbol{j}$ "cut off," combine with second consonant $z$ "push" to give jazz "to cut off ..."; jaza "to divide, ..."; jazar "to slaughter, ..."; jazic "break apart"; jazam "cut off"; but with $\boldsymbol{r}$ "shake" to give jarad "to peel"; and with $\boldsymbol{d} \boldsymbol{h}$ "point" to give jadhar "uproot"; jadham "cut off"? It seems rather as if the second consonant is part of the meaningless remainder. I don't so much deny the possibility of such interpretations working in some way, for example if the individual consonant meanings get more refined. But I feel certain that focusing on initial consonants is a more helpful working hypothesis for the present.

I also cannot fully accept Magnus's suggestions of universality and sound-symbolism, partial and tentative as they are (for she does note that more unrelated languages are likely to differ more). For example, her English $\boldsymbol{p}$ and $\boldsymbol{b}$ seem to be mostly the opposite of my Hebrew $\boldsymbol{p}$ and $\boldsymbol{b}$ which certainly opposes universal sound-symbolism (although at the same time conversely supporting a partial, varying universality). A preliminary analysis of Mandarin, Russian, and Latin has revealed very different meanings for each language, although greater similarity between related ones; for example, Mandarin $\boldsymbol{p}$ seems to mean smooth.

I do not deny (or accept) the widespread speculation of soundsymbolic origins of key-consonants or of the roots of language generally. (But, for example, Gazov-Ginzberg, in a fairly extensive listing of such hypothetical roots in Semitic, gives no preference to single consonants over sequences of two to four consonants.) I simply see as the urgent need a cataloguing of the meanings of key-consonants in various languages, and find the traditional assumption of arbitrariness a useful working assumption in my own research along these lines.

Taylor \& Taylor's classic article (1965) argues against soundsymbolism (using the traditional example of high vowels indicating smallness and the like), but does so by testing reactions of speakers of different languages. While I am indifferent to the issue of soundsymbolism, as noted, I cannot help noticing that it completely ignores the claim originally made by Bolinger, namely that specific sound-sequences smaller than morphemes (perhaps even single initial consonants, as claimed here) can be identified with specific meanings. Linguistics made notable progress centuries ago by the insistence that comparisons between languages be made on the basis of comprehensive descriptions of individual languages. I here suggest a similar recommendation for the study of sound-symbolism.

In any case, within Skousen's framework, it is possible to view the 
entire lexicon as a single extended table: Any words perceived by any speaker as similar in sound and meaning can conceivably produce new formations, as well as helping memory for native speakers. However, the primacy of the initial consonant would seem to have overriding importance for the organization of the lexicon. That is, the key-consonant lexicon exemplified above would seem to be a sample for an interesting hypothesis about the way in which the lexicon is actually organized in the mind. (Interestingly, while there is no alphabetic order, the listing is an "alphabetic" grouping by initial phoneme.)

Let me attempt applying key-consonant theory to English, however tentatively: It is my belief, although one for which I have examples rather than proofs, that Bolinger's assonances (consonant-cluster submorphemes) in English are an irregular sub-phenomenon of key-consonants, e.g. \#gl-, which I reanalyzed as flash, is rather a sub-phenomenon of an English key-consonant \#g- meaning overwhelm (other example: gloom, great, grand, God).

However, rimes are simply an additional phenomenon, similar to the other submorphemes but independent; the consonant alternations of Semitic, which Bohas's theory of 'matrices' also includes, go beyond keyconsonant theory as such, although phonologically similar consonants are observed to exhibit similar (even overlapping) meanings (and permutations go beyond it as well, with initial permutations even cutting across it).

Similar and overlapping meanings are captured by key-consonant tables, in which key-consonants are placed adjacent to each other. As noted, adjacent consonants are often but not always phonetically similar.

For reader interest, a tentative table of English key-consonants is provided in table fifteen, following my current analysis. It may be interesting for the reader, whether a native speaker of English or not, to find examples (including metaphoric extensions, such as die, for $\boldsymbol{d}$ ) - and also counter-examples, of which there are many (the majority). For the keyconsonant meanings, I have provided actual example-words (e.g. choosing grand instead of overwhelm for $\boldsymbol{g}$ ).

\begin{tabular}{|c|c|c|c|}
\hline $\begin{array}{c}\boldsymbol{p} \\
\text { point }\end{array}$ & $\begin{array}{c}\boldsymbol{t} \\
\text { travel }\end{array}$ & $\begin{array}{c}\boldsymbol{k} \\
\text { cut }\end{array}$ & $\begin{array}{c}c h \\
\text { chor }\end{array}$ \\
\hline $\begin{array}{c}b \\
\text { buloe }\end{array}$ & $\underset{d r o n}{d}$ & $\underset{g r a n d}{g}$ & $\underset{j}{\boldsymbol{j}}$ \\
\hline
\end{tabular}

If, as I have suggested, initial consonants predominate even beyond Semitic, this means that the Semitic languages may well serve by pro- 
viding a relatively clear example of an otherwise obscure structure - this, in contrast with e.g. consonantal roots, for which so such general significance has been proposed, as far as I know.

\section{A Note on Arabic Diglossia and Teaching.}

Is key-consonant theory applicable only to formal, written Arabic, and not to colloquial, spoken Arabic? In Hebrew, because of the many phonological complications (many-to-many correspondences between consonants and sounds), key-consonant theory is far less directly applicable to speech than in Arabic. But even Arabic dialectal variation has little general significance: Whether $[\mathrm{j}]$ or $[\mathrm{g}]$ is the pronunciation of the Arabic consonant makes no difference to the coherence of roots using this consonant. And it makes little difference to the envisaged key-consonants table which pronunciation is used, since pronunciation is in any case not the sole criterion for placement (as clearly in the case of similar consonants like $\boldsymbol{r}-\boldsymbol{z}$ or $\boldsymbol{k}-\boldsymbol{l}$ ).

Obviously, however, the kind of contemplation needed to hypothesize meanings in context, and further "triangulate" them with the help of keyconsonant theory, is more suitable to the self-paced reading process, rather than listening comprehension. For speaking, the key-consonant system can contribute only indirectly, by helping the learner recall (i.e. acquire and access) words more effectively in advance of any particular conversation. Key-consonant theory thus dramatizes the gap between different language-skills, a gap which I feel is in any case far underemphasized in ordinary curriculum (especially in Less Commonly Taught Languages such as Arabic), with its far greater emphasis on linguistic structure per se.

In Arabic as in Hebrew, as an additional example of the under-emphasis on the distinction between language skills, there is also the special problem of diglossia, which is often decided artificially in favor of written language: In both languages, the written form is often regarded as uniquely "correct," so that learners are pushed away from their natural preference for speaking - and their desire to speak spontaneously; and indeed in-class speech tends to be in English where it could have been in Spoken Arabic. (Waszkowski 2000) In Arabic, the resulting artificiality is extreme, as if one were to tell a prospective student of French: "French is just slang. You'll be better off traveling around Europe using Latin, which is the universal European language"-with the result that shopping is avoided in some elementary curricula, in spite of its communicative importance. (As one Arabic teacher put it: "Fish'? Why teach 'fish'? It's not a beautiful word at all!") This analogy with Latin is ad- 
mittedly only partial, but it is meaningful.

Arabic is a fascinating language to teach, largely because it is so much more difficult than other languages (again, for an American) and thus confronts the teacher with so many more dimensions of challenge than European languages. Solutions to problems of Arabic teaching are likely to be massively helpful in teaching easier languages like Spanish or French. However, Arabic will be able to exploit its potential only to the extent that it actually solves the greater problems that it presents, rather than lagging behind Western languages methodologically, as at present, in which the newest published textbooks make no pretense of catching up to those of Western European languages.

The lexical dimension is the dimension confronted in key-consonant theory, which offers a way for students of Arabic to learn the meanings of new roots, and even guess their meanings in context, in a way that is apparently not available in European languages, at least not on the same level. But let us consider the significance of this fact: If one were to visit a class in any foreign language, one might guess that the grammar of a language is its most important dimension, judging by the time spent discussing it in class. Students are typically sent home to learn the vocabulary, as if it were some small incidental detail. But isn't it obvious that vocabulary is a far larger, far more important part of a language than its grammar? What can one express without vocabulary, no matter how sophisticated one's command of grammar? It might be objected that, with vocabulary, there is nothing to discuss structurally: Words just are, and you can do nothing but list them-in a dictionary, or in a list to be memorized. But that is the problem: What is clearly the largest, most important dimension of language doesn't even offer us a handle to discuss it, except in lists - unless key-consonant theory can be formulated and applied successfully. If it can, it will allow students to liberate themselves from dependence on glossaries and dictionaries: One can hardly read a newspaper in the way a newspaper is designed to be read with dictionary in hand; nor can one acquire glossaries to accompany them. Successful reading depends on a solution to the lexical problem, such as the solution offered by key-consonant theory.

Perhaps the key-consonant system is simply a unique feature of the Semitic languages, like consonantal roots. Or perhaps, even more interestingly, the Semitic languages offer us a hint of lexical relationships that exist in language in general-perhaps being only more transparent in Semitic - even to the point of usability in L2 teaching, while existing as well in some less obvious form in other languages, as most interestingly suggested for English by Magnus. 


\section{BIBLIOGRAPHY}

Attaoui, Jamila. 2003. Defining and Defending Educated Spoken Arabic. MA thesis, San Diego State University, San Diego, California. bar-Lev, Zev. 1984. "Arabic Ungrammar." Teaching Language through Literature 23:3-15.

— 1991. "Glifim be-hora ${ }^{\circ}$ at "arvit" (Glyphs in teaching Arabic), Bita ${ }^{\circ}$ on la-Moreh le-Arvit, no. 9.

- 1993. "Sheltered-Initiation Language Learning." Applied Language Learning 4, nos. 1, 2.

- 1994a. "An Unnatural Approach.” Mid-Atlantic Journal of Foreign-Language Pedagogy 2.

-1 1994b. "Introduction." Statement of Competencies in Languages, Phase II: Japanese, Mandarin, Chinese, Russian. Sacramento, California: Academic Senates of California.

- 1995. "Spontaneity in Elementary Arabic." In Teaching Arabic as a Second Language, ed. Mahmoud Al-Batal. Provo, Utah: American Association of Teachers of Arabic, Brigham Young University. . 1996. "Acquisition Theory and Usable Hebrew." Shofar, 14, no. 4. . 1999a. "Beyond Proficiency in a Japanese Mini-Course." In Yuki Johnson, ed., Proceedings of the Ninth Lake Erie Teachers of Japanese Conference. Ann Arbor, Michigan: University of Michigan.

- 1999b. "Key-Letters and the Invention of the Alphabet."The Glyph, March.

- 2000a. Hebrew Free Speech. San Diego California: LARC Press, San Diego State University.

2000b. "Methodological Innovation \& Mechanical Media." In Yoshiko Saito-Abbott, Richard Donovan, Thomas F. Abbott, eds., Emerging Technologies in Teaching Languages \& Cultures. San Diego California: LARC Press, San Diego State University, [2003].

. 2000c. Arabic Free Speech. San Diego California: LARC Press, Mini-Course Series, San Diego State University

- 2001a. Shush and Say 'SIX.' San Diego California: LARC

Press, San Diego State University.

- 2003a. "Lexicon and Key-Letters in Hebrew," Shofar, summer. . 2003b. "Otiyot mafteah be-civrit" (Key-letters in Hebrew), HaDo $^{\circ}$ ar 82 , no. 4 .

- 2004. "Kabbalah \& Hebrew Key-Letters." Bulletin of Hebrew Higher Education.

. 2006. "Shorshe ha-shorashim" (Roots of roots). Hed ha-Ulpan he-Hadash, no. 90. 
Bar Yohai, Shim ${ }^{c}$ on. 5758. Sefer ha-zohar. Jerusalem: Yerid ha-Sfarim. Ben-Dror, Gilah. 1997. 22 ha-otiyot: Masoret u-mistorin (The twentytwo letters: Tradition and mystery). Rosh ha- ${ }^{\mathrm{c}}$ Ayin, Israel: Prolog.

Blau, Joshua. 1981. The Renaissance of Modern Hebrew and Modern Standard Arabic. Berkeley: University of California Press.

Bohas, Georges. 1997. Matrices, étymons, racines. Leuven: Peeters.

Bolinger, Dwight. 1965. "Rime, Assonance, and Morpheme Analysis." In Forms of English. Cambridge, Massachusetts: Harvard University Press.

Brace.

Celce-Murcia, Marianne, ed. 1991. Teaching English as a Second or Foreign Language. 2nd ed. Boston: Heinle \& Heinle.

Chomsky, William (Ze'ev). 1972. Ha-lashon ha-'ivrit be-darkhe hitpathutah (The Hebrew language in its development). Jerusalem: R. Mas.

Clark, Matityahu. 1999. Etymological Dictionary of Biblical Hebrew. Jerusalem: Feldheim.

Court de Gébelin, Antoine. 1776. Histoire naturelle de la parole. Paris: Boudet.

Diakonoff, Igor Mikhailovitch. 1975. "On Root-Structure in Proto-Semitic". In James \& Theodora Bynon, eds., Hamito-Semitica. The Hague: Mouton.

Ehret, Christopher. 1995. Reconstructing Proto-Afroasiatic (Proto-Afrasian). Los Angeles: University of California Press.

Fabre-d'Olivet, Antoine. 1815. La langue hébraïque restituée, Paris: Bernard Laville.

Fogelman, Jennifer. 2003. Submorphemes in Lexicon and Foreign-Language Teaching. MA thesis, San Diego State University, San Diego, California.

Ferguson, Charles. 1959. “The Arabic Koine.” Language 35 (4): 616-30.

-1963. "Diglossia." In Anwar Dil, ed., Language Structure and Language Use. Stanford: Stanford University Press.

Gazov-Ginzberg, Anatolī̌ Mikhaĭlovich 1965. Byl li iazyk izobrazitelen $v$ svoikh istokakh? (Was language imitative in its origins?). Moscow: Nauka.

Ginzburg, Rabbi Yitshak. 1995. The Alef-Beit. Northvale, New Jersey: Jason Aronson.

Hassanein, Ahmed Taher \& Kamar Mostafa Abdou. 1991. The Concise Arabic-English Lexicon of Verbs in Context. Cairo: American University in Cairo Press. 
Hinton, Leanne, Johanna Nichols, \& John Ohala. 1994. Sound Symbolism. Cambridge: Cambridge University Press.

Hodge, C. T., ed. 1971. Afroasiatic: A Survey. The Hague: Mouton.

Hoffman, Edward. 1998. The Hebrew Alphabet: A Mystical Journey. San Francisco: Chronicle Books.

Hurwitz, Solomon Theodore Halévy. 1966. Root Determinatives in Semitic Speech. New York: AMS Press.

Ibn Khaldūn. 1958. The Muqaddimah: An Introduction to History. Translated by Franz Rosenthal. Volume 3. New York: Pantheon.

Ifrah, Georges, 1998. The Universal History of Numbers. New York: Wiley.

Kaplan, Aryeh, 1979. The Bahir. York Beach, Maine: Samuel Weiser.

- 1997. Sefer yetzirah. York Beach, Maine: Samuel Weiser.

Kautsch, E. 1910. Gesenius' Hebrew Grammar, translated by A. E.Cowley. 2nd edition. Oxford: Clarendon.

Krashen, S. \& T. Terrell. 1983. The Natural Approach. San Francisco: Alemany.

Landau, Jacob. 1959. A Word Count of Modern Arabic Prose. New York: American Council of Learned Societies.

Lipiner, Elias. 1989. Hazon ha-otiyot (The vision of the letters). Jerusalem: Magnes.

Lory, Pierre. 1996. "La mystère des lettres en terre d'islam." Annales de philosophie (Beirut, Lebanon) 17: 101-9.

Magnus, Margaret. 1999a. A Dictionary of English Sound. MS (forthcoming). 1999b. Gods of the Word: Archetypes in the Consonants. Kirksville, Missouri: Thomas Jefferson Press.

Malik, Khalid M. 2000. Ayn al Miftah (The Visual Key). Birmingham: Ghouri.

Marr, Samantha (in progress). Key-Consonant Theory with Special Reference to Arabic. MA thesis, San Diego State University, San Diego, California

Mazhar, Muhammad Ahmad. Arabic: The Source of All the Languages. Liechtenstein: Kraus.

Mehandjiyska, Mirena. 1998. Review of Georges Bohas, Matrices, etymons, racines: elements d'une theorie lexicologique du vocabulaire arabe. Middle East Studies Association Bulletin, vol. 32, no. 2, Winter 1998.

Miller, Edward Frederick. 1966. The Influence of Gesenius on Hebrew Lexicography. New York: AMS Press.

Munk, Rabbi Michael L. 1983. The Wisdom in the Hebrew Alphabet. 
Brooklyn, New York: Mesorah.

Nation, I. S. P. 1990. Teaching and Learning Vocabulary. New York: Harper \& Row.

Percival, W. Keith. 1984. "The Reception of Hebrew in Sixteenth-Century Europe: The Impact of the Cabbala." Historiographia Linguistica 11 (1/2). Also in:Antonio Quilis and H.-J. Niederehe, eds., The History of Linguistics in Spain. Amsterdam Studies in the Theory and History of Linguistic Science, series 3, vol. 34. Amsterdam and Philadelphia: John Benjamins, 1986.

Ratcliffe, Robert R. 2001. "Analogy in Semitic Morphology: Where Do New Roots and New Patterns Come From?” In Andrzej Zaborski, ed., New Data and New Methods in Afroasiatic Linguistics: Robert Hetzron in Memoriam. Wiesbaden: Harrassowitz.

Rollins, Peter. 1980. Benjamin Whorf: Lost Generation Theories of Mind, Language, and Religion. Ann Arbor: University Microfilms.

Saenz-Badillos, Angel. 1993. A History of the Hebrew Language. Cambridge: Cambridge University Press.

Schimmel, Annemarie. 1975. Mystical Dimensions of Islam, Chapel Hill, North Carolina: University of North Carolina Press.

Skoss, Solomon L. 1955. Saadia Gaon, The Earliest Hebrew Grammarian. Philadelphia: Dropsie College Press.

Skousen, Royal. 1989. Analogical Modeling of Language. Dordrecht: Kluwer. 1992. Analogy and Structure. Dordrecht: Kluwer. 1995. "Analogy: A Non-Rule Alternative to Neural Networks." Rivista di linguistica 7: 213-31.

—. 1998. "Natural Statistics in Language Modeling." Journal of Quantitative Linguistics 5: 246-55.

Smith, Frank, 1971. Understanding Reading. New York: Holt, Rinehart \& Winston.

— ed. 1973. Psycholinguistics and Reading. New York: Holt, Rinehart \& Winston.

Taylor, Insup, \& M. M. Taylor. 1965. "Another Look at Phonetic Symbolism." Psychological Bulletin 64: 413-27.

Vychicl, Werner. 1987. "The Origin of the Hamito-Semitic Languages." In Herrmann Jungraithmayr \& Walter W. Müller, eds., Proceedings of the Fourth International Hamito-Semitic Congress. Amsterdam: J. Benjamins.

Voigt, Rainer M. 1988. Die infirmen Verbaltypen des Arabischen und das Biradikalismus-Problem. Stuttgart: Franz Steiner.

Waszkowski, Denise. 2000. The Problems of Teaching Modern Standard 
Arabic as a Second Language to Beginning Adult Students. MA thesis. San Diego State University, San Diego, California.

Whorf, Benjamin. 1978. Language, Thought, and Reality. Cambridge, Massachusetts: MIT Press.

Wehr, Hans (J M. Cowan, ed.). 1976. Dictionary of Modern Written Arabic. Ithaca, New York: Spoken Language Services.

Wirszubski, Chaim. 1989. Pico della Mirandola's Encounter with Jewish Mysticism. Cambridge, Massachusetts: Harvard University Press.

Zaborski, Andrzej. 1975. "Note on Biconsonantal and Triconsonantal Roots in Cushitic." Folia Orientalia 16.

. 1991. "Biconsonantal Roots and Triconsonantal Root Variations in Semitic: Solutions and Prospects". In Alan Kaye, ed., Semitic Studies in Honor of Wolf Leslau, vol. 2. Wiesbaden: Harrassowitz. 